\title{
Influence of Processing on the Microstructure and the Mechanical Properties of Zn/HA8 wt.\% Biodegradable Composite
}

\author{
Jan Pinc ${ }^{1,2}$, Eva Miklášová ${ }^{1}$, Filip Průša ${ }^{1}$, Jaroslav Čapek ${ }^{2}$, Jan Drahokoupil ${ }^{2}$, Dalibor Vojtěch ${ }^{1}$ \\ ${ }^{1}$ University of Chemistry and Technology, Prague, Department of Metals and Corrosion Engineering, Technicka 5, Pra- \\ gue, 166 28, Czech Republic. E-mail: miklasovae89@gmail.com, prusaf@vscht.cz, vojtechd@vscht.cz \\ ${ }^{2}$ Institute of Physics, Czech Academy of Sciences (CAS), Na Slovance 1999/2, 18221 Prague 8, Czech Republic. \\ E-mail: pinc@fzu.cz, capekj@fzu.cz,draho@fzu.cz
}

\begin{abstract}
Zinc-based materials show large potential to become biodegradable materials with ideal corrosion behavior in the body environment. In this study, a zinc composite containing 8 wt. \% of hydroxyapatite (HA) was prepared by spark plasma sintering (SPS) and characterized from a point of view of the microstructural and mechanical properties. The influence of pre-processing (milling) of the powders on the microstructure after the sintering was studied. The materials prepared by the milling and subsequent sintering showed insufficient cohesion due to the wrapping of $\mathrm{Zn}$ by $\mathrm{HA}$ particles and possible oxidation of zinc particles. Compressive and flexural tests of sintered materials prepared without any pre-processing confirmed the role of hydroxyapatite as a defect in the Zn/HA8_SPS structure. The results of the hardness measurement suggest that the HA does not affect the behavior of the zinc matrix.
\end{abstract}

Keywords: Zinc, Hydroxyapatite, Biodegradable composites, Ball milling, Spark plasma sintering

\section{Introduction}

Biodegradable metals are a group of materials which should replace polymeric biodegradable materials with insuffient mechanical properties for some applications that are connected mainly with the bone healing process. Recently, the biodegradable metals (magnesium, iron, zinc and their alloys) are extensively studied [1]. Some magnesium-based materials have already been patented for applications in implatology; however, those materials possess some limitations for some applications. Biodegradable materials must fulfil several basic conditions. The most important of them are connected with the mechanical and corrosion behaviour and non-toxicity of the corrosion products $[1,2]$.

Zinc is an essential element with various functions in human organism [3]. One of most important function, in connection with potential use of zinc-based materials as bone implants, is the cooperation of zinc in the bone mineralization process $[4,5]$. On the other hand, the use of zinc in implantology is limited by its recommended daily allowance (RDA) and its poor mechanical properties, especially in the as-cast state. The RDA value is approximately 10-15 mg, which means that the corrosion of the implant must not cause ion release exceeding this value [6]. The zinc-based materials are considered mainly for applications such as stents, augmentations, temporary orthopaedic implants and screws. In order to achieve sufficient mechanical properties for such applications different processes have been investigated. For example, alloying with vaious elements, such as magnesium, calcium, strontium, aluminium, silver or copper, have been investigated [7-9]. The other considered approach how to improve zinc properties is preparation of its composites reinforced with particles of hydroxyapatite (HA) [10].

Hydroxyapatite $\left(\mathrm{Ca}_{5}\left(\mathrm{PO}_{4}\right)_{3} \mathrm{OH}\right)$ is an inorganic part of human bone and due to that it is used for the enhancing of the biological interaction between implant and the tissue. Hydroxyapatite is often used for the preparation of layers on the biomaterials [11, 12], alone as a scaffold $[13,14]$ or as a reinforcement in composites $[15,16]$. The mechanical performance of pure HA is strongly affected by the preparation process and the porosity of the final product. In some cases, it is comparable and in some cases even better than that of cortical bones [17].

Spark plasma sintering is a newly developed method of sintering which allows to prepare materials with almost theoretical density and fine-grained microstructure [18, 19]. In comparison with the conventional sintering methods, the time and temperature of the SPS proces are significantly lower, which can result in finer structure of the prepared samples [18].This method of densification is suitable especially in the case of materials with low recrystallization temperature, for example for Zn-based materials.

According to the best of our knowledge, the $\mathrm{Zn} / \mathrm{HA}$ composites with metal matrix have beed studied poorly and only one publication have been published until this moment [10]. This paper is focused on the characterization of microstructure and mechanical properties of $\mathrm{Zn} / \mathrm{HA}$ composites prepared by spark plasma sintering process and combination of ball milling with subsequent sintering. This study describes the relation between the methods of processing and resulting mechanical properties.

\section{Experiment}

The powders of pure zinc (AlfaAesar, purity 99.9\%) and hydroxyapatite (Medicoat, medical purity) were used as initial materials. The powders were mixed and homogenized in a weight ratio $92: 8$ by a Turbola T2C mixer. The homogenization was performed at 50 rotations per minute (RPM) for 20 minutes. Prepared powder was devided in half and a part of the mixed powder was milled using a high energy ball mill Retch Emax. Stearic acid in the amount of $2 \mathrm{wt}$. \% was added to the powder mixture as a lubricant. In order to investigate the influence of milling 
parameters, the powders were milled at 300, 500 and 700 RPM for 10 and 30 minutes under an argon atmosphere. The weight ratio between the mixed powder and the zirconia balls was $1: 15$. The milled powders were analyzed using X-ray fluorescent spectrometer ARL 9400XP (XRF). The milled powder mixtures were sintered using a HP D 10 furnace type (SPS) at a temperature of $300^{\circ} \mathrm{C}$ using a force of $10 \mathrm{kN}$ for $10 \mathrm{~min}$. The second part of the powder mixture (unmilled) was sintered immediately after the mixing using SPS. The conditions of the proces were the same as it was mentioned above. The prepared materials were $20 \mathrm{~mm}$ in diameter and about $5 \mathrm{~mm}$ in heigt. Pure zinc, prepared in the same ways, was used as a referent material. The materials were primarily characterized from the microstructural point of view. Based on the the microstructure, some samples were selected and their mechanical properties were studied as well. For the microstructural characterization, the samples were cut in the direction perpendicular to the pressing and both sections (longitudinal and cross-section) were ground using SiC papers up to $\mathrm{P} 4000$. Subsequently, the samples were electrochemically polished in a mixture of phosphoric acid and ethanol (50:50) for 9 minutes using a voltage of $4 \mathrm{~V}$ against a stainless steel cathode. The polished samples were observed using an optical microscope Olympus PME3 and a scanning electron microscope TESCAN

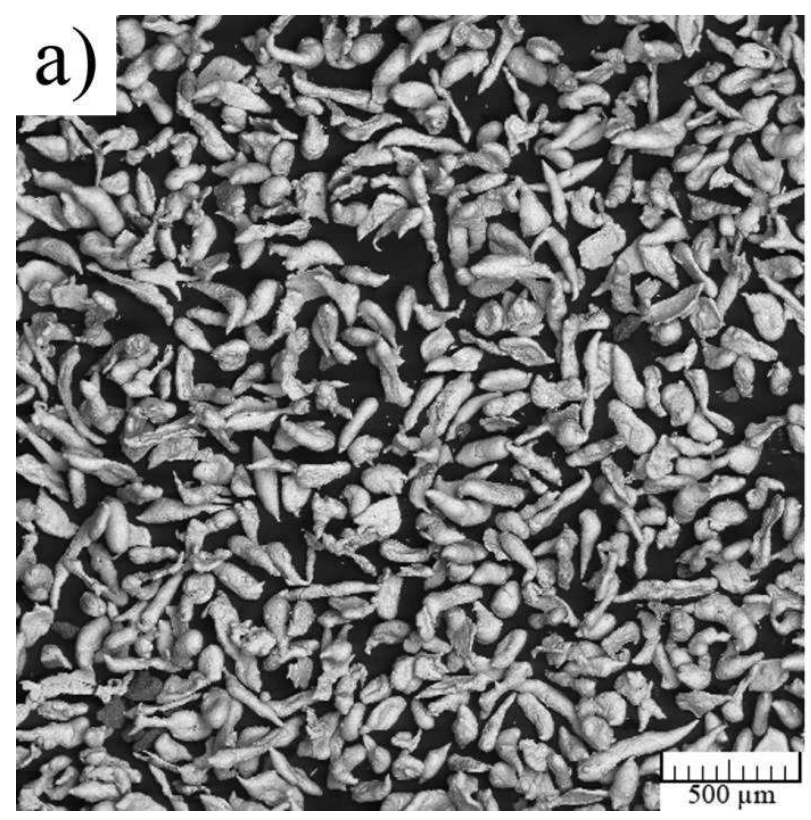

VEGA 3 LMU with an energy dispersive spectrometer OXFORD Instruments INCA 350 (SEM-EDS). The distribution and area fraction of hydroxyapatite in zinc matrix was evaluated by the ImageJ software. In case of sintered samples without pre-processing the compressive and flexural properties were measured using an universal testing machine LabTest 5.250SP1-VM at a room temperature. The dimensions of the samples used for the compressive and flexural testing were $4 \times 4 \times 6 \mathrm{~mm}, 3 \times 3 \times 20$ $\mathrm{mm}$ respectively. Vickers hardness was measured using two different (HV1, HV0.1) loads in order to adjust hardness of the individual components and the hardness of the whole composite.

\section{Results and Discussion}

\subsection{Initial powders characterization}

The morphology of the initial powders used for the preparation of the specimens is shown in Fig. 1. The particles of pure zinc were elongated in one direction and the size of the particles in this direction was up to $500 \mu \mathrm{m}$ (Fig 1a). In addition, diameter of the cylindrical zinc particles was approximately $100 \mu \mathrm{m}$. On the contrary, the hydroxyapatite sharp-edge particles had the size up to 250 $\mu \mathrm{m}$ in average and porosity approximately $15 \%$.

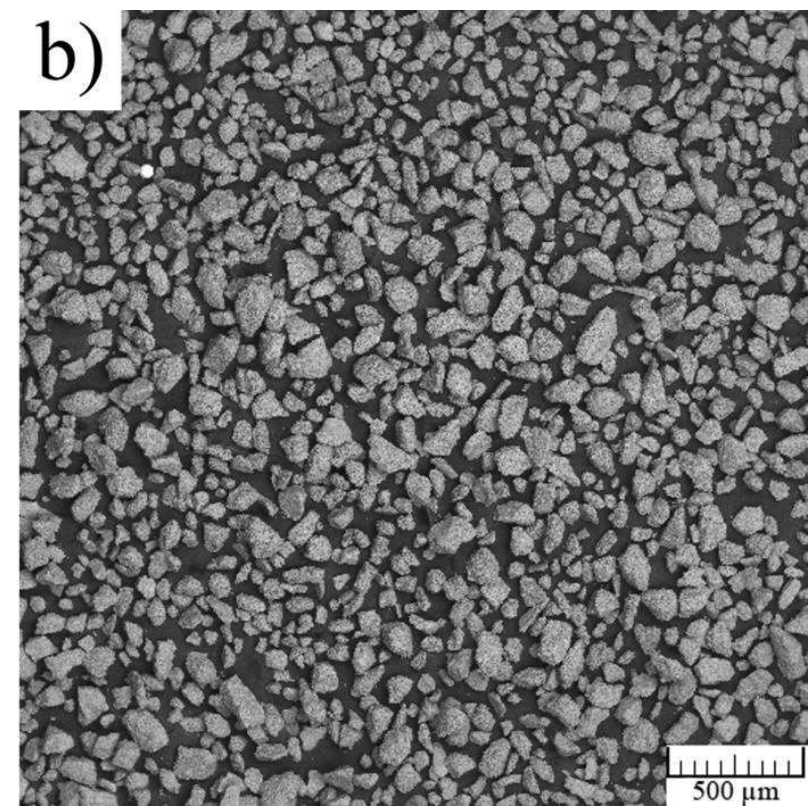

Fig. 1 The initial powders of a) zinc and b) hydroxyapatite.

\subsection{SPS without pre-processing}

The microstructure of $\mathrm{Zn} / \mathrm{HA} 8$ _SPS after sintering process is shown in Fig. 2. In the images it is visible that the material was porous and the porosity consisted of three different areas where the pores were occured. Except the pores in HA particles the pores were situated predominantly between zinc and hydroxyapatite particles which is visible in Fig. 2a. The minor part of pores in the structure was between zinc particles in the zinc matrix. The porosity is crucial for the material properties, due to that the porosities $(\varepsilon)$ of prepared samples were also theoretically calculated using equations:

$$
\begin{gathered}
\rho_{\text {theor. }}=\rho_{\mathrm{Zn}} \cdot \mathbf{w}_{\mathrm{Zn}}+\rho_{\mathrm{HA}} \cdot \mathbf{w}_{\mathrm{HA}}\left[\mathrm{g} \cdot \mathbf{c m}^{-3}\right] \\
\varepsilon=\left(1-\frac{\rho_{\text {real }}}{\rho_{\text {theor }}}\right) * 100[\%]
\end{gathered}
$$

Where:

W... mass fractions of zinc and HA [-]

$\rho .$. densities of zinc and HA $\left[\mathrm{g} \cdot \mathrm{cm}^{-3}\right]$

$\rho t_{\text {heor... theoretical density }\left[\mathrm{g} \cdot \mathrm{cm}^{-3}\right]}$

$\rho_{\text {real } \ldots} .$. table density of zinc $\left[\mathrm{g} \cdot \mathrm{cm}^{-3}\right]$

According to the calculations, the porosity of pure zinc and the composite after sintering was approximately $4.1 \%$ and $15.5 \%$ respectively. The theoretical porosity 
(Eq. 1) of Zn/HA8_SPS composite (15.5\%) was calculated in order to determinate the influence of the HA particles porosity to the absolute value. This calculation confirmed that the HA particles porosity formed only a minor part $(1.2 \%)$ from the total porosity and the major part was formed by the pores situated in zinc matrix (between $\mathrm{Zn}$ $\mathrm{Zn}, \mathrm{Zn}$-HA particles). It suggests that the corrosion process will be probably speed up by exposition of larger zinc area. In the structure, holes in the material were also

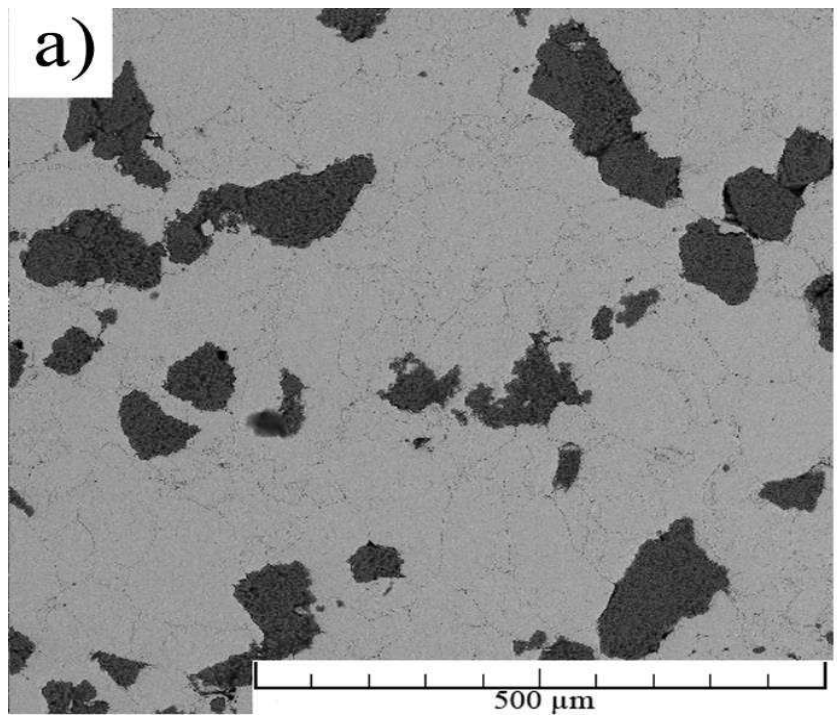

present. Those holes were caused by breaking out of the HA particles. It means that the sintering conditions were insufficient for the creation of connection between individual hydroxyapatite particles and between HA and zinc particles. It suggests that the HA particles were captured by surrounding zinc in the structure mechanically. The grain size of the zinc materix ranged from 5 to $40 \mu \mathrm{m}$ and no significant differences in the grain size of pure zinc and Zn/HA8_SPS composite were observed.

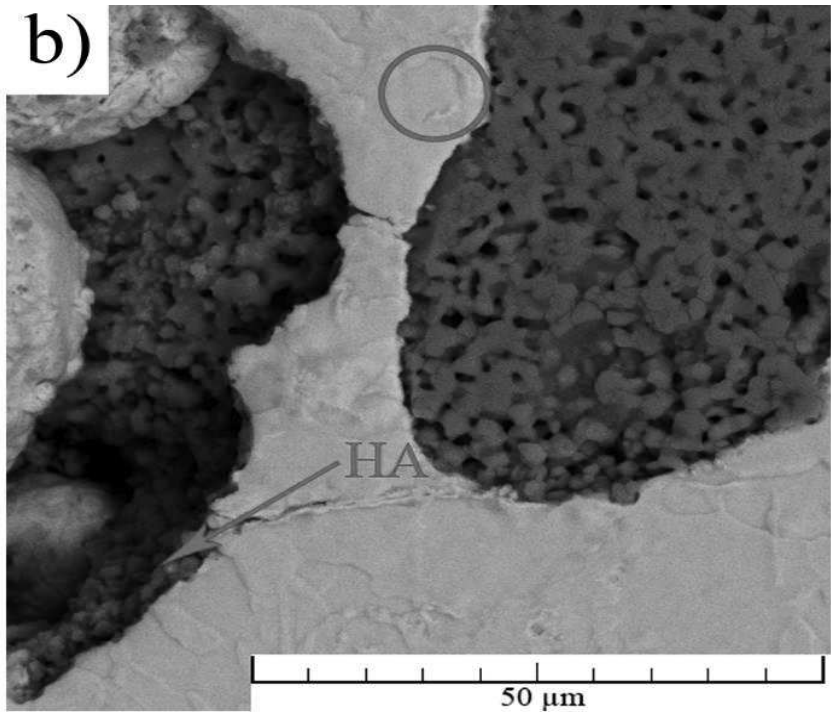

Fig. 2 SEM images of Zn/HA8_SPS composite microstructure with highlighted grain and HA stacked on the zinc particles

\subsection{Ball milling process}

The microstructures of the samples prepared by SPS of the powders milled under different conditions (time and RPM) are shown in Fig. 3. The milling was performed in order to prepare material with homogeneous distribution of HA in the structure. After the sintering the samples showed signs of poor cohesion and higher HA content. The microstructure analysis revealed that the behavior of the resulting materials was connected with the size of the hydroxyapatite particles. It is clearly visible in Fig. 3a that the milling at 300 RPM for 10 minutes was insufficient for breaking down of all HA particles. Due to

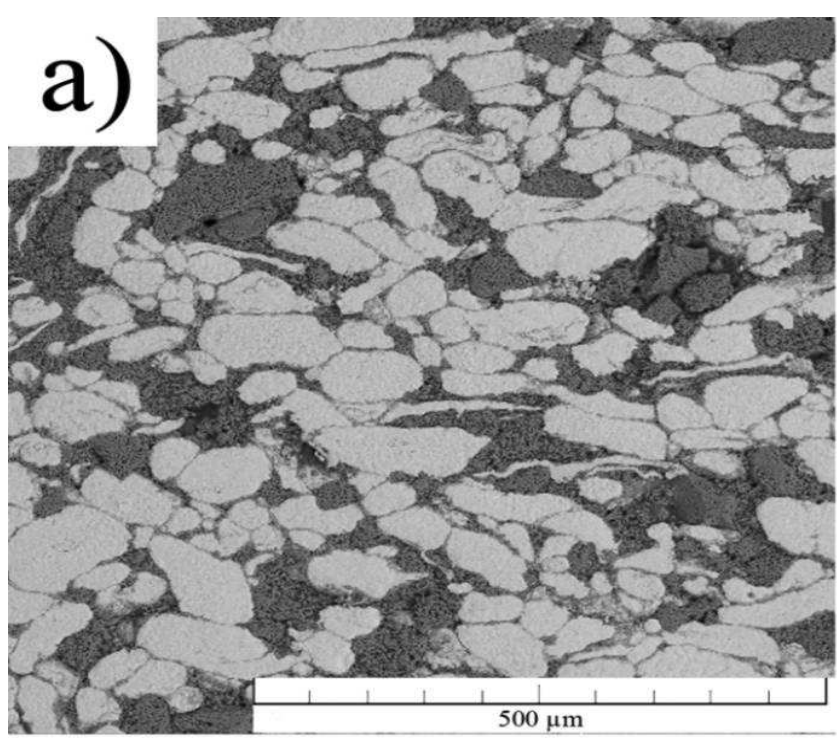

that the finer particles of hydroxyapatite embedded the zinc particles and coarser HA particles were not sufficiently intercorporated in the structure. It was confirmed that the milling time affected only the size of HA particles (Fig. 3a,b). On the contrary, the RPM parameter significantly affected the size of HA particles as well as the level of the deformation of zinc particles (Fig. 3a,c,d). Milling at 700 RPM led to a high level of the deformation of the $\mathrm{Zn}$ particles. In this case, the $\mathrm{Zn}$ particles were elongated and their surface was higher. As a consequence, the particles were fully wrapped by HA particles which disallowed the diffusion connections between $\mathrm{Zn}$ particles (Fig.3d) resulting into poor cohesion.

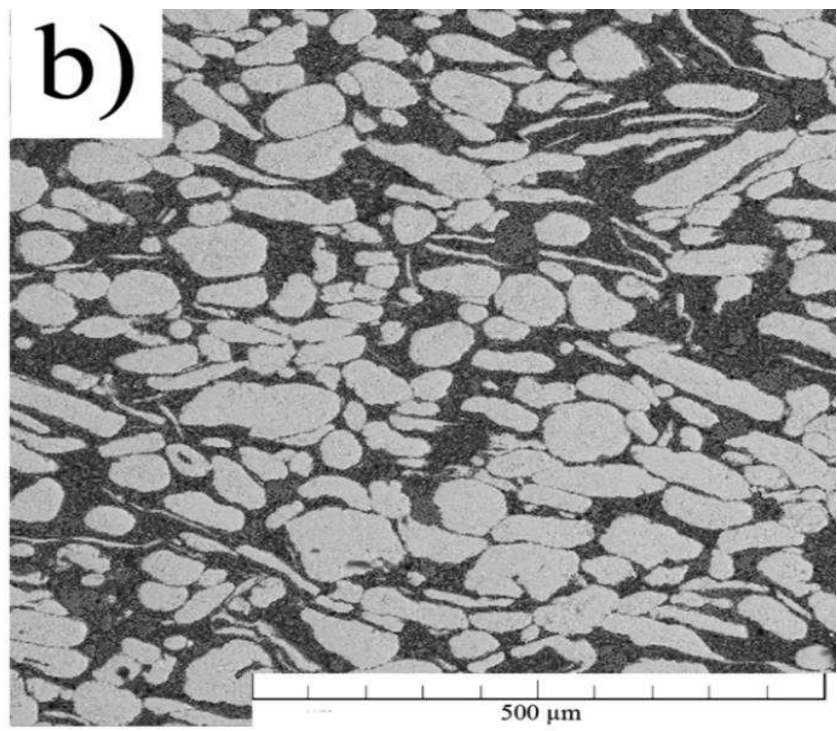



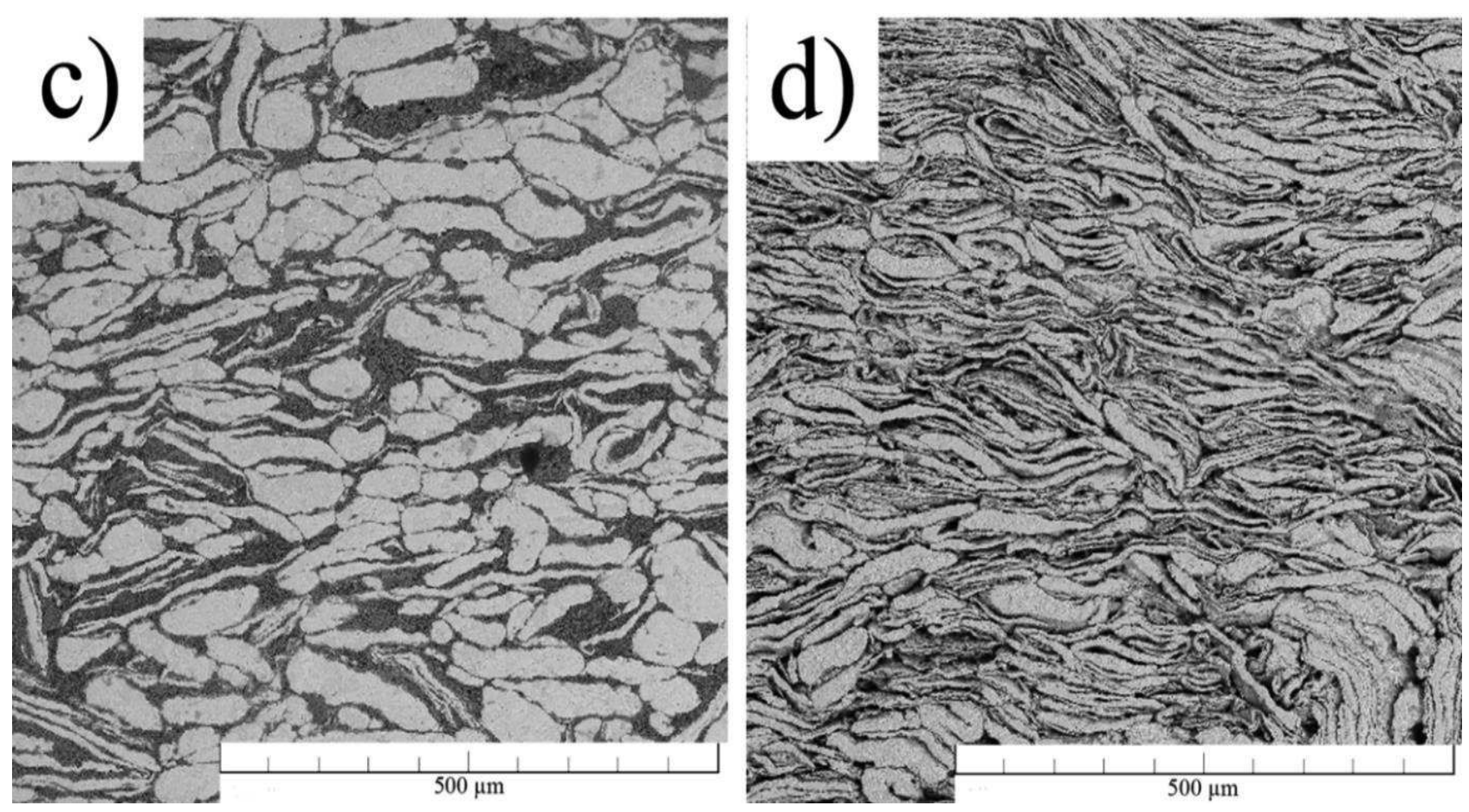

Fig. 3 Microstructures of samples milled a) for 10 minutes at 300 RPM, b) for 30 minutes at 300 RPM, c) for 10 minutes at 500RPM and d) for 10 minutes at 700 RPM.

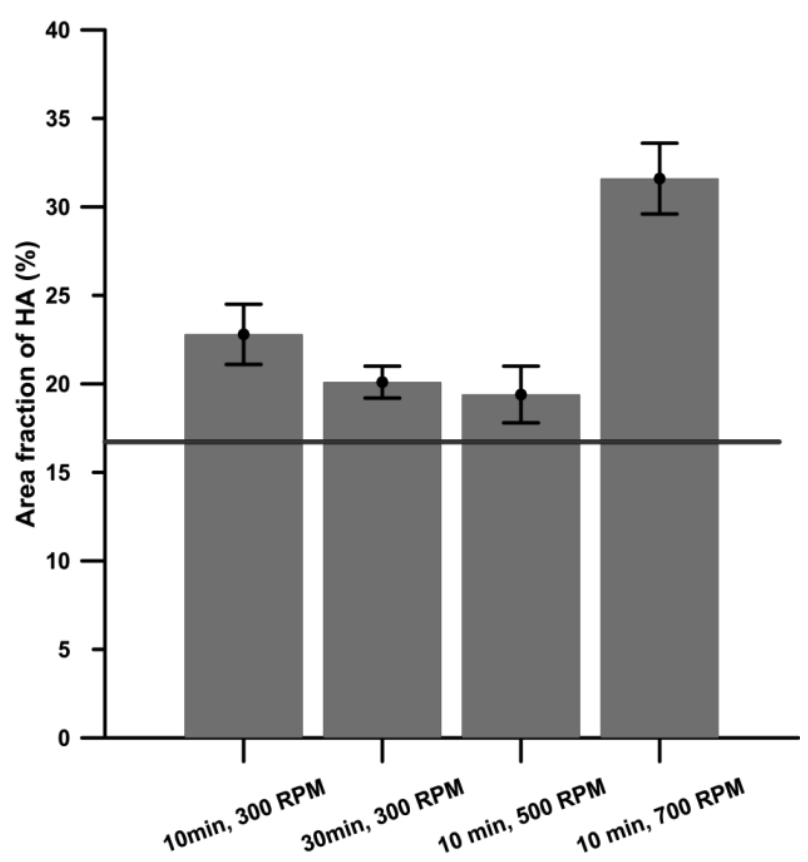

Fig. 4 Area fraction of HA in milled samples. The blue line highlights the desired composition.

Despite the presence of $2 \mathrm{wt} \%$ of stearic acid which acted as a lubricant, the content of zinc decreased in the material due to sticking of zinc particles to the milling tank. This was also evident from the results of the image analysis (Fig.4), which confirmed that the content (area fraction of HA) was not the same for all pre-milled samples. Based on the results obtained by XRF analysis an exact surplus of zinc was added into the tank prior the milling. Regardless, it was found that the behaviour of the powder during the milling was unpredictable and the process is unusable for those materials.

\subsection{Mechanical properties}

In Fig 4 the compressive and flexural curves of the Zn/HA8_SPS composite and pure Zn are shown. The pure $\mathrm{Zn}$ was prepared in the same way as the composite and was used as a referent material. According to the information obtained by the characterization of microstructures only the mechanical properties of samples without the milling before the sintering were measured. It was found, that independently on the testing method the particles of hydroxyapatite in the structure acted as defects and deteriorated the mechanical properties of Zn/HA8_SPS compared to the pure zinc prepared in the same way.On the contrary, the addition of HA leads to enhancement of biological properties and the samples do not lose the plastic behavior during the compressive testing. The interesting fact was that the strength of pure zinc was higher approximately about $30 \%$ in the case of both compressive and flexural tests. It suggests that the sintering parameters were sufficient for creation of high quality diffusion connections between zinc particles and that the decrease of strength was caused by the amount of brittle HA in the material. In addition, the porosity was connected with the HA particles content and deteriorated the mechanical properties. Information from the fracture surfaces after the flexural testing was in good agreement with the flexural curves. It means that the fracture surface of pure zinc contained visible regions with signs of plastic deformation. On the contrary, in case of Zn/HA8_SPS those signs were negligible. 
a)

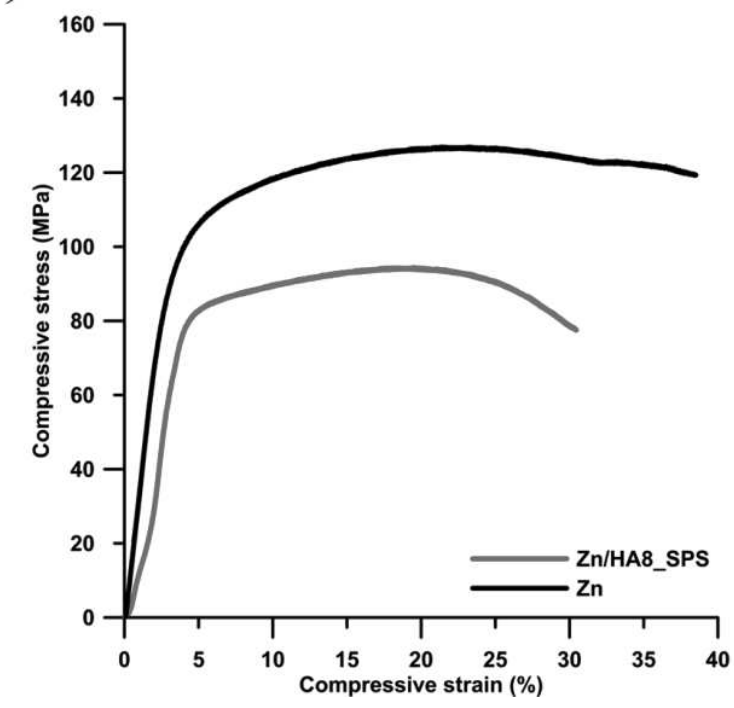

b)

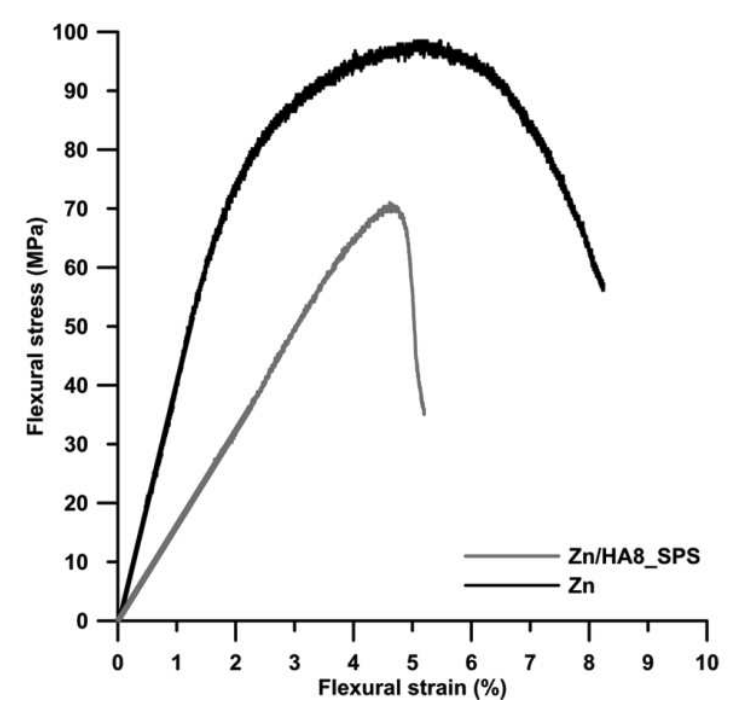

Fig. 4 Engineering a) compressive and b) flexural stress-strain curves of Zn/HA8_SPS composite and pure Zn

In addition, the Vickers harnesses (HV1, HV0.1) of those materials was measured (Table 1). The HV0.1 measurement confirmed that the hardness of zinc matrix was not affected by the presence of HA particles. Interesting fact was that the values of pure zinc and $\mathrm{Zn} / \mathrm{HA}$ composite were within the error same. It suggests that the HA particles were not involved into stress transmission during the testing which is in good agreement with information mentioned above.

Tab. 1 Overview of hardness value for Zn/HA8_SPS and Zn samples

\begin{tabular}{|l|c|c|}
\hline Material & HV1 & HV0.1 \\
\hline Zn/HA8_SPS & $34.3 \pm 4.5$ & $43.4 \pm 4.3$ \\
\hline Zn & $38 \pm 2.1$ & $40.1 \pm 2.7$ \\
\hline
\end{tabular}

\section{Conclusion}

The influence of processing on the mechanical performance was observed and described in detail. The conclusions can be summarized in those points:

1. Sintered samples without pre-processing showed sufficient cohesion with porous structure $(15 \%)$.

2. Unpredictable behavior of powders during milling do not allow use this method before the SPS process.

3. The measurements of compressive and flexural properties confirmed the role of HA as a defect in the structure.

4. In addition, the hardness measurements revealed that the HA particles did not affect the zinc matrix in the point of view of strengthening.

5. According to the results, the mechanical properties can be enhanced by the decrease of HA content and by suitable method of processing (for example by increasing of preassure or temperature) which will be able to decrease the porosity of material.

6. The Zn/HA8_SPS materials show potential to be a new biodegradable material, however, more information for this statement is needed (corrosion and biological testing).

\section{Acknowledgement}

The authors would like to thank to the Czech Science Foundation (project no. 18-06110S) and specific university research (MSMT no. 21-SVV/2019) for the financial support.

\section{References}

[1] ZHENG, Y.F., GU, X.N. AND WITTE, F. (2014). Biodegradable metals. In: Materials Science and Engineering: R: Reports, Vol. 77, No. 1-34.

[2] YUN, Y., DONG, Z., LEE, N., LIU, Y., XUE, D., GUO, X., KUHLMANN, J., DOEPKE, A., HALSALL, H.B., HEINEMAN, W., SUNDARAMURTHY, S., SCHULZ, M.J., YIN, Z., SHANOV, V., HURD, D., NAGY, P., LI, W. AND FOX, C. (2009), Revolutionizing biodegradable metals. In: Materials Today, Vol. 12 , No. 10 , pp. 22-32.

[3] RINK, L. Zinc in human health. 2011, Amsterdam: IOS Press. xiii +577 pp.

[4] YAMAGUCHI, M., OISHI, H. AND SUKETA, Y. (1987), Stimulatory effect of zinc on bone formation in tissue culture. In: Biochemical Pharmacology, Vol. 36, No. 22, pp. 4007-4012.

[5] BROWN, E.D., CHAN, W. AND SMITH, J.C. (1978), Bone Mineralization during a Developing Zinc Deficiency. In: Proceedings of the Society for Experimental Biology and Medicine, Vol. 157, No. 2, pp. 211-214.

[6] FUNG, E.B., RITCHIE, L.D., WOODHOUSE, L.R., ROEHL, R. AND KING, J.C. (1997), Zinc 
absorption in women during pregnancy and lactation: a longitudinal study. In: The American Journal of Clinical Nutrition, Vol. 66, No. 1, pp. 80-88.

[7] LI, H.F., XIE, X.H., ZHENG, Y.F., CONG, Y., ZHOU, F.Y., QIU, K.J., WANG, X., CHEN, S.H., HUANG, L., TIAN, L. AND QIN, L. (2015), Development of biodegradable $\mathrm{Zn}-1 \mathrm{X}$ binary alloys with nutrient alloying elements $\mathrm{Mg}, \mathrm{Ca}$ and Sr. In: Scientific Reports, Vol. 5, No. 10719.

[8] NIU, J., TANG, Z., HUANG, H., PEI, J., ZHANG, H., YUAN, G. AND DING, W. (2016), Research on a $\mathrm{Zn}-\mathrm{Cu}$ alloy as a biodegradable material for potential vascular stents application. In: Materials Science and Engineering: $C$, Vol. 69, No. 407-413.

[9] SIKORA-JASINSKA, M., MOSTAED, E., MOSTAED, A., BEANLAND, R., MANTOVANI, D. AND VEDANI, M. (2017), Fabrication, mechanical properties and in vitro degradation behavior of newly developed $\mathrm{ZnAg}$ alloys for degradable implant applications. In: Materials Science and Engineering: C, Vol. 77, No. 1170-1181.

[10] YANG, H., QU, X., LIN, W., WANG, C., ZHU, D., DAI, K. AND ZHENG, Y. (2018), In vitro and in vivo studies on zinc-hydroxyapatite composites as novel biodegradable metal matrix composite for orthopedic applications. In: Acta Biomaterialia, Vol. 71, pp. 200-214.

[11] LUGOVSKOY, A. AND LUGOVSKOY, S. (2014), Production of hydroxyapatite layers on the plasma electrolytically oxidized surface of titanium alloys. In: Materials Science and Engineering: C, Vol. 43, pp. 527-532.

[12] MAYR, H., ORDUNG, M. AND ZIEGLER, G. (2006), Development of thin electrophoretically deposited hydroxyapatite layers on TiAl6V4 hip prosthesis. In: Journal of Materials Science, Vol. 41, No. 24, pp. 8138-8143.

[13] MA, J., WANG, C. AND PENG, K.W. (2003), Electrophoretic deposition of porous hydroxyapatite scaffold. In: Biomaterials, Vol. 24, No. 20, pp. 3505-3510.

[14] SON, J.S., APPLEFORD, M., ONG, J.L., WENKE, J.C., KIM, J.M., CHOI, S.H. AND OH, D.S. (2011), Porous hydroxyapatite scaffold with three-dimensional localized drug delivery system using biodegradable microspheres. In: Journal of Controlled Release, Vol. 153, No. 2, pp. 133-140.

[15] KANE, R.J. AND ROEDER, R.K. (2012), Effects of hydroxyapatite reinforcement on the architecture and mechanical properties of freezedried collagen scaffolds. In: Journal of the Mechanical Behavior of Biomedical Materials, Vol. 7, pp. 41-49.

[16] KANE, R.J., CONVERSE, G.L. AND ROEDER, R.K. (2008), Effects of the reinforcement morphology on the fatigue properties of hydroxyapatite reinforced polymers. In: Journal of the Mechanical Behavior of Biomedical Materials, Vol. 1, No. 3, pp. 261-268.

[17] AKAO, M., AOKI, H. AND KATO, K. (1981), Mechanical properties of sintered hydroxyapatite for prosthetic applications. In: Journal of Materials Science, Vol. 16, No. 3, pp. 809-812.

[18] MAMEDOV, V. (2002), Spark plasma sintering as advanced PM sintering method. In: Powder Metallurgy, Vol. 45, No. 4, pp. 322-328.

MUNIR, Z.A., ANSELMI-TAMBURINI, U. AND OHYANAGI, M. (2006), The effect of electric field and pressure on the synthesis and consolidation of materials: A review of the spark plasma sintering method. In: Journal of Materials Science, Vol. 41, No. 3, pp. 763-777. 